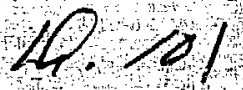

PPPL -1582

$0 \mathrm{C}-20 \mathrm{a}$

\title{
A STUDY OF THE MASS AND ENERGY RESOLUTION OF THE \&|B CHARGE EXCHANGE ANALYZER FOR TFTR
}

BY

R. KAITA AND $S$, S, MEDLEY

\section{PLASMA PHYSICS LABORATORY}

\section{MASTER}

\section{Princeton UNIVERSITY 1. PRINCETON, NEW JERSEY}

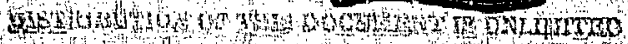




\author{
A STUISY OF THE NASS ANI) ENERG RESOL.IJTION OF THE \\ E!B CHARGE EXCHANGE ANALYZER FUR TFTR \\ R. Kaitia and S. S. Medley \\ Plasina Physirs Laboratory, Princeton Iniversity \\ Princeton, N.J 08544
}

\begin{abstract}
ABSTRAAT
The churge exchange diagnostir: Lor Tl:TR requires simultuneous multusperie $\left(\mathrm{H}^{+}, \mathrm{U}^{+}, \mathrm{T}^{+}\right)$analysis of particles in the energy range of $0.5-150 \mathrm{keV}$. The analy,rer design chosen to provide this rapability employs a wide gap seni-circular region of superimposed parallel electric and magnetic fields to accomplish mass and energy resolution, respectively. Combined with a large area, multi-anode mirrochannel plate detector, this arrangement will enable the energy distributions of protons, deuterons, and tritons to be measured concurrestly as a function of time during each discharge. A computer simulation progrun for ralculating iun trajectories through the analyzer was written that includes a reaistic model of the inagnetic and electrostatic fringe fields. This report presents the results of a study of the proposed E || B anilyzer, and it reveals that the fringe fields are not detrimental to the performance of the analyzer.
\end{abstract}

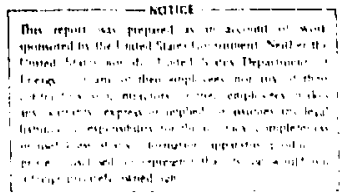


1. INIR: : :THOS

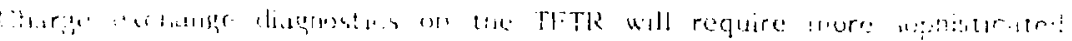

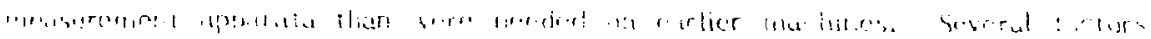

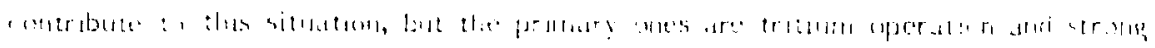

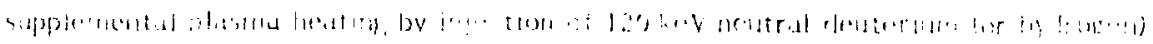

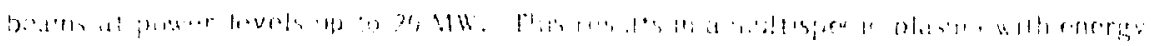

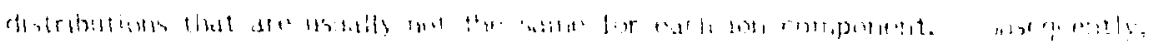

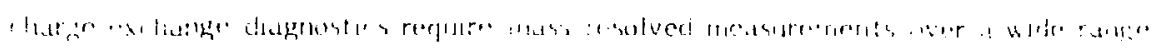

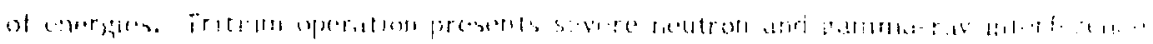

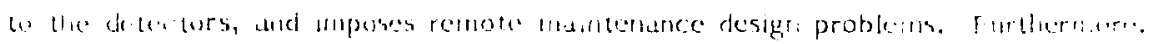

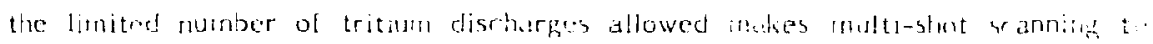

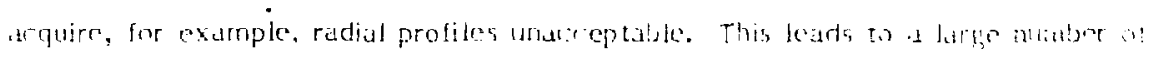

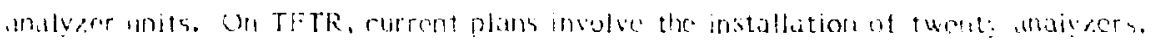

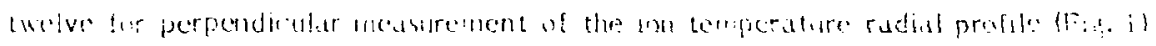

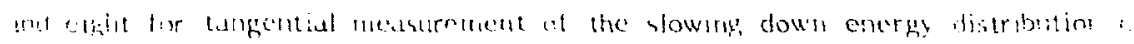

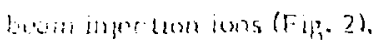

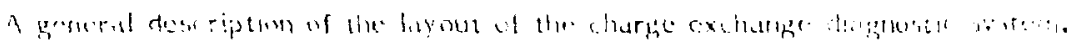

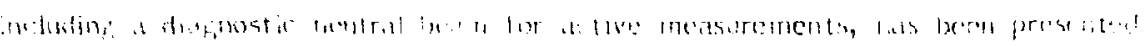

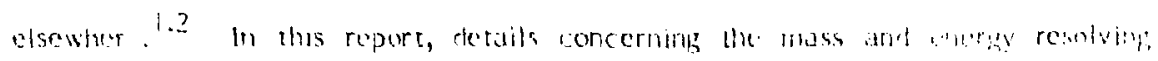

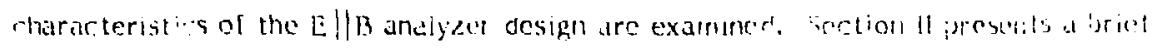

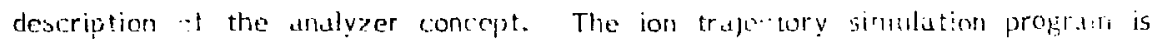
Jiscussed in ser. ill, followed by a description of the magnetic (Sec. IV) and clectri: (Sec. V) field modeling used in the program. Kesults of the stirdy are prosentrd in Sec. VI and the conclusions in Sec. VII. 


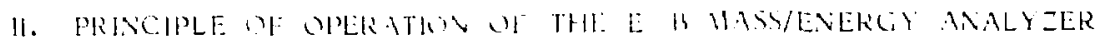

The basic operatimg principle of the Paralle! olectric ulid magnetic field

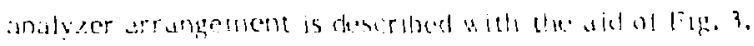

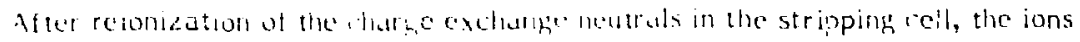

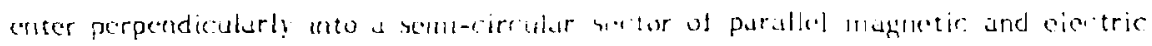
fields. In these fields, the Lorentit tores

$$
m \dot{y}-q(y \times \underline{B}+\xi)
$$

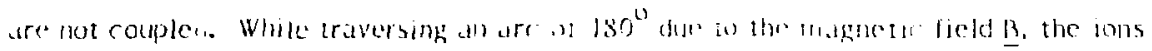

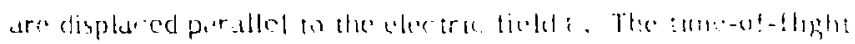

$$
\mathbf{t}_{j}=\frac{\bar{B}}{\mathrm{~B}}\left(\frac{\mathrm{m}}{\mathrm{c}}\right)_{j}
$$

between entering the field region and arriving at the rollector is independent of the initial velority for uny given ion speries (In/e). The lisplacement $Y_{j}$ of the : th spcicies purallel to the electric field is giver by

$$
y_{j}=\overline{-}^{2}\left(\frac{1}{12}\right)\left(\frac{m}{c}\right)_{j} \text {. }
$$

which is also independent of velouity, so that all partives of a given tule ratio are displaced along the clectic fietd direction by the salik umount. The ion species (m/e) $j$ entering with velocity $v_{k}$ is disp!aced a distince

$$
z_{j k}=\frac{2}{B}\left(\frac{m}{c}\right)_{j} v_{k i}
$$

from the entrance Doint in a direction perpendicular to $\underline{v}_{k} \times \underline{B}$. The collection plane thus exhibits parallel columns of analyzed ions, each column containing energy dispersed iors of given (m/e) ratio. The detector is located in the collection plane and consists of a planar thannel electron multiplier array (CEMA) as shown in FiE. 4. The CEMA is provided with three rectangular, semi-coniinuous active area strips, one 


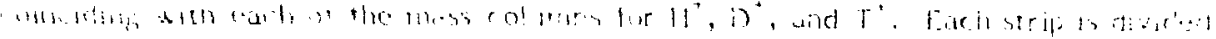

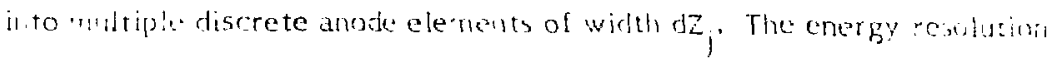

$$
\frac{\Delta E}{i}+\frac{d z_{j}}{z_{j}}
$$

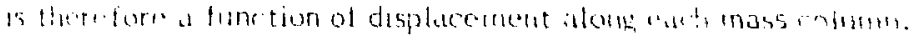

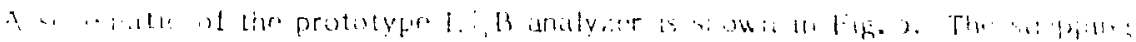

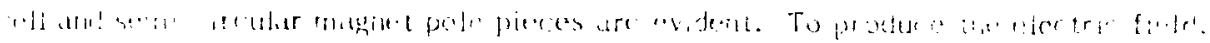

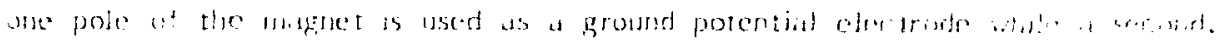

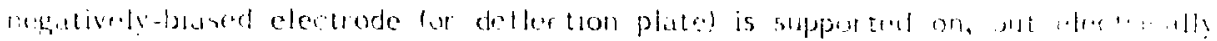

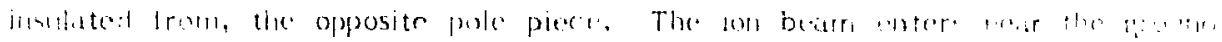

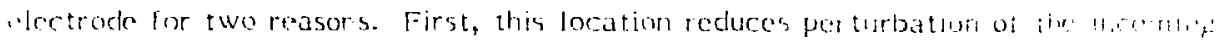

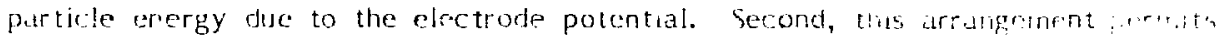
utilization of the [ull separation of the magnet gap. Even so, artequate sp.ttid!

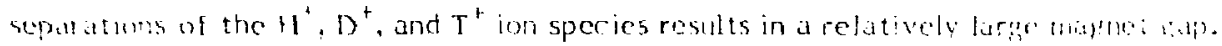
Frou the relation for the magnetic field strength $\mathrm{h}$ (in ganss),

$$
13 \quad 1.25 \frac{\mathrm{NI}}{\mathrm{d}} \text {. }
$$

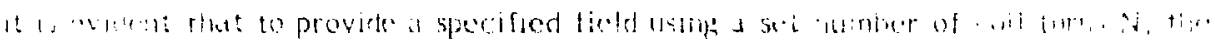

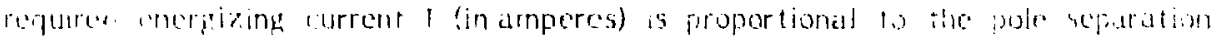
त(in connanelors). In adjition to the sizable magnet power requrements arising lrom?

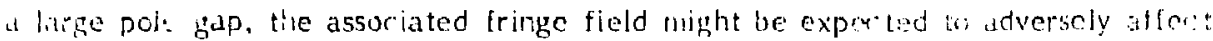
the ion trajestories.

Alternative configurations are possible which reduce the polc separation whilipreserving the E $\| B$ analysis concept. Although a detailed discussion is beyomd the srope of this report, two such alternatives will be described briclly. rirst, sottic degroe of reduction in pold separation can be achieved by requiring that only part of the necessary spatial dispersion of the ion species takes place while the ions ate 


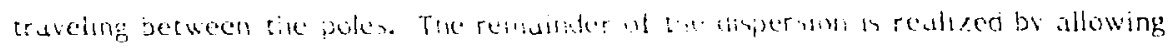

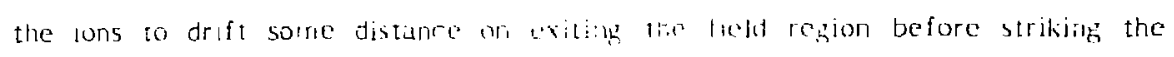
retector. If the detector plarie remuins purallel to, but is dispiared awdy from the atraight celge of the' mitgine, the mass columes become parabolit in shape, with lower

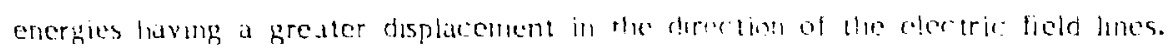

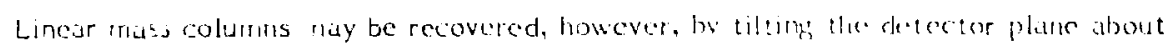

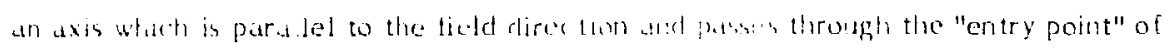

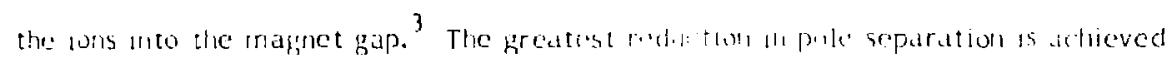

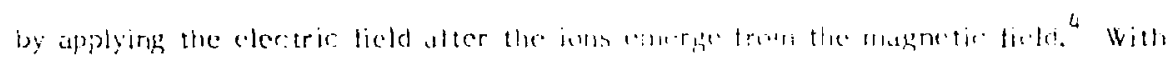

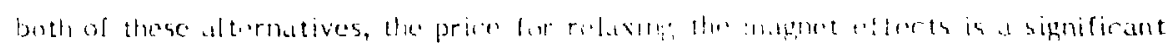
increase in the overall dimensions of both the andalyer and the de ter tor to encompass the same energy range. Since the present upplicultinf requires shielding the interior of the analyzer against stray mannetio fields dur to TFTK, moreasing the size of the analyzer also teacs to more massive enchosure walls.

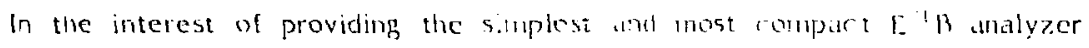
possible far TFTR, it was decided to exurnime nore thoroughly the configuration shown in Fig. 5. Through careful design of the mugnet freld coili and operation in a

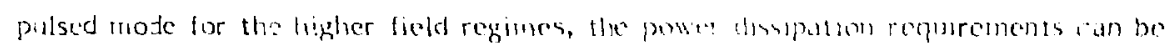
reduced to it least some degree. This refort ad Iressim aperifically the effert of the electric and inagnetic fringe fields on the perlormance of the analyzer.

\section{ION TRAJECTORY SMULATLN IMUUR IU}

The program (C:ENA.FOR) to be described here ivolved from a llonte carlo code previously used to simulate ion trajectories in the PLT charge exchange analyzer, ${ }^{5}$ and later for a modification of the 1 'L $L$ system to provide an $E$ ! B ficld contiguration for the PDX thermal analyzer system." The varlicr program. however. was extensively rewritten to account for the wifferent inagnetic/electrir field 


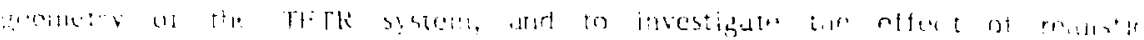

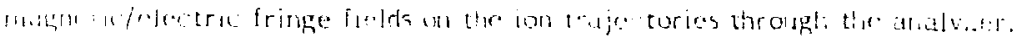

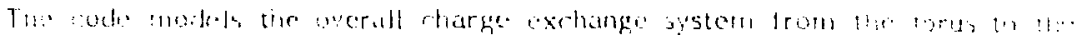

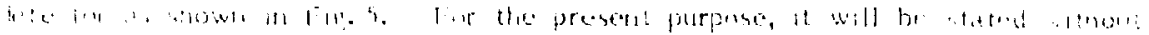

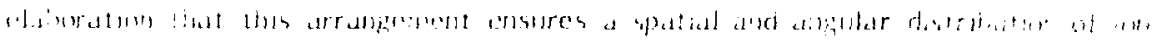

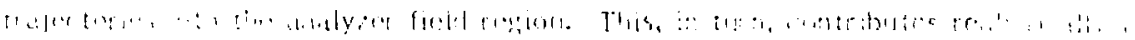

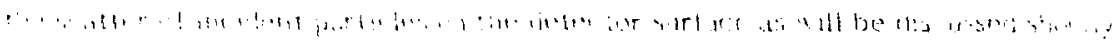

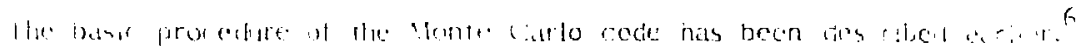

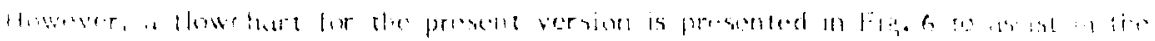
1.

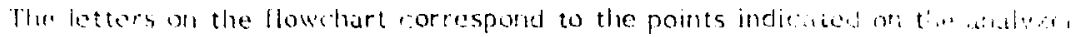

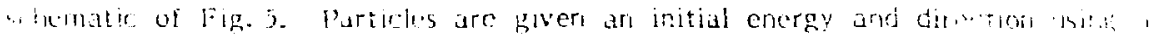

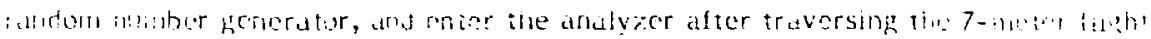

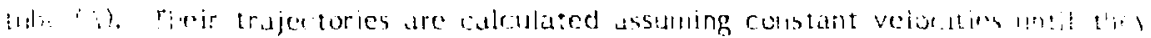

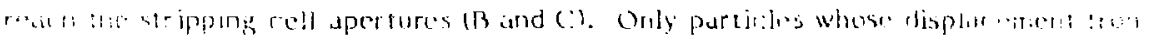

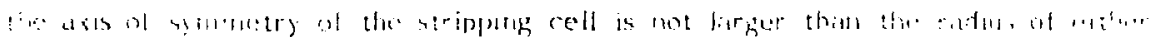

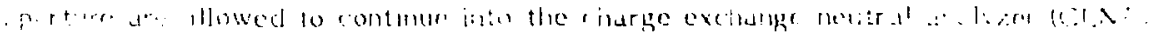
'ini,

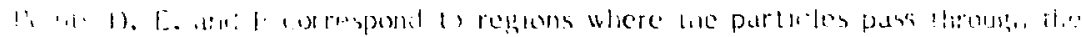

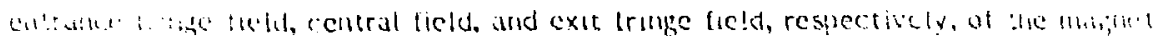

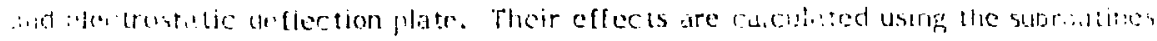

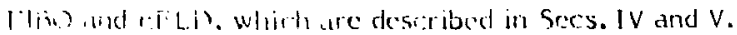

is in Rel. 6, the motion of a particle of mass m, unit charge, and velocity : $:$ : $\therefore$ verned $h m^{2} v^{2} P=v B$ in the analyzing magnet. This implics a radius of curvature (in (in)

$$
1 . \quad \sqrt{20.7} m \bar{E}
$$


where $E$ is the kinetic energy in keV, $B$ is in kilogauss, and $m$ is in A.MU. The clectrostatic plate deflects the particle (Lnit charge) due to a force $F=F=V / d$, where $V$ is the plate voltage and $d$ is the plate hap. Since the plate and the magnet cover the same region, a distance $I=-R$ traveled through the magne: means a total verticul displacement of

$$
\begin{aligned}
& Y=\frac{\frac{1}{2} v^{4 E d}}{} \\
& =8.51 \frac{m V}{B^{2}}
\end{aligned}
$$

where d was taken to be $6 \mathrm{~cm}$. The virtue of plawing the plate within the magnet is evident here in that $Y$ is independent of energy; for a fixed $B$ and $V$, the vertical deflection is only a function of the mass $\mathrm{m}$. Thus, $B$ and $f=v / d$ are the only quantities needed to predict the point on the Jetector plane at which a particle of a certain energy and mass will impart.

In pract: $:$, particles will enter the magnet and plate region noar the ground plane electrode. In the code, a reasonable valie of $0.5 \mathrm{~cm}$ was adopted. the boundary conditions require that the magneti: anci electrostatic fields do not instantancously vanish at the edge of the region, and that the flax density increases there as one approaches either pole iace or plate. The present simulation code calculates $B$ and as a function of horizontal and vertical ( $x$ and $y$ ) position for a mare accurate determination of $R$ and $Y$ than was possible in the earlier version. Particies that do not strike the deflection plate and pole piece have their coordinates on the detector plane (G) recurded and plotted. All others are stored in arrays corresponding in the points along the CENA system at which they are lost.

\section{B-FIELD CALCULATIONS IN THE PRESENCE OF IRON BOUNDARIES}

A set of FORTRAN subroutines was lirst written to find the R-lield due to a number of conductors in the presence of iron, ${ }^{7}$ which ran be called by the trajectory 


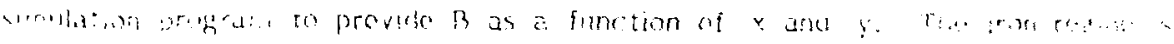

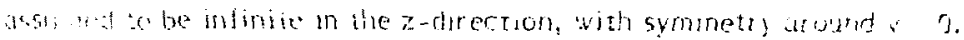

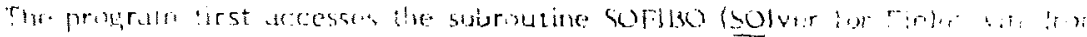

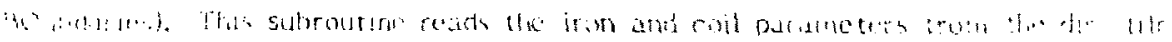

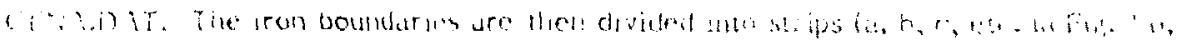

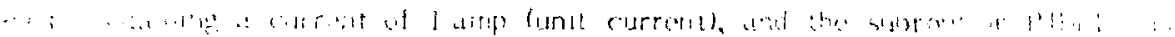

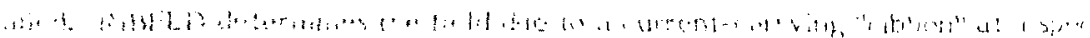

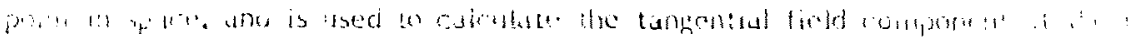

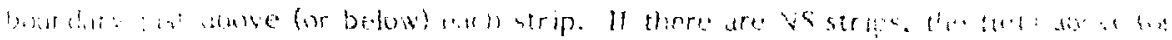

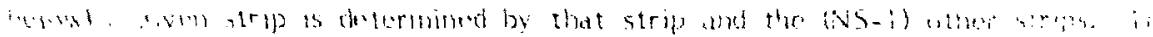

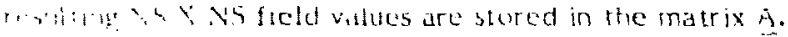

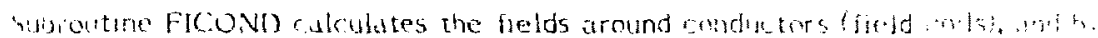

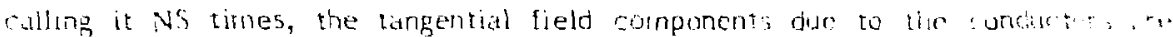

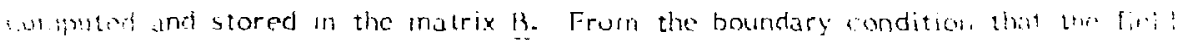

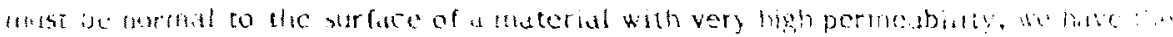
iditis.s.

$$
\wedge_{i j} I_{i}-1,0
$$

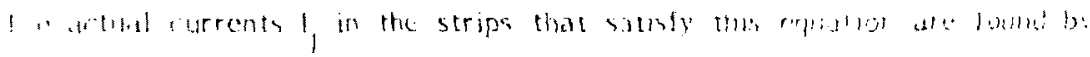

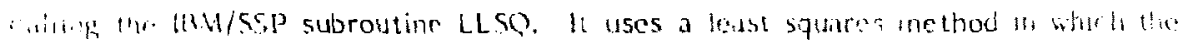

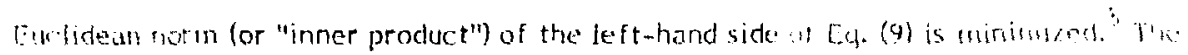
rurit:nts are adjusted for finite permeability (f) by the multiphative fur wor li! f: Whet,

$$
\text { MUFAC }-\frac{1-\mu}{1+\mu}
$$

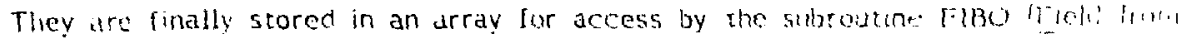

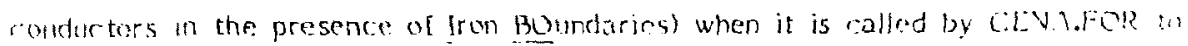
Galculute the wotual n-field. 
FlR ralls RIBFLD to get the B-ficld contributions from the currents ralculated by SOFIBO, and FICOND to get the B-ticld contributions from the conductors. It thus determines the $x$ and $y$ tield components (i3 and by at ihe rourdindtes (x,y) passed to it by SENA.FOR.

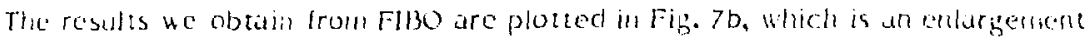

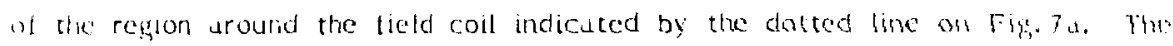

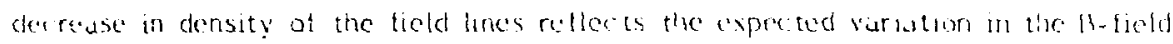
streftith with horbontal distance outward trom the magnet.

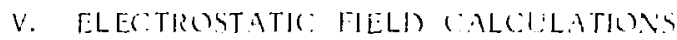

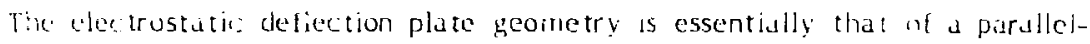
plute capucitor in frec space, with strcamlines and equipotentials us in Fin. Sa. If we in this into the w-plane and sulve for the complex potential $\Phi$ (Fin. Sb).

$$
\begin{aligned}
& x=x+i y-\frac{d}{\div}\left[\ln w \cdot \frac{1}{2}(1-x=)\right] \\
& =\left[\ln (u+k) \cdot \frac{1}{2}\left(1-u^{2}-v\right]\right.
\end{aligned}
$$

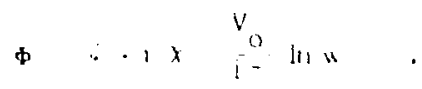

Therefore,

$$
\left.z=\frac{d}{\pi} \frac{i \pi}{V_{0}}+\frac{1}{2}\left[1-e^{2\left(\frac{i \pi}{V_{0}}+\right)}\right]\right\}
$$

We want to find

$$
\begin{aligned}
F & =9 \\
& =\mid \frac{d \Phi}{d z}
\end{aligned}
$$

tor particles of unit charge. From Eq. (13), 


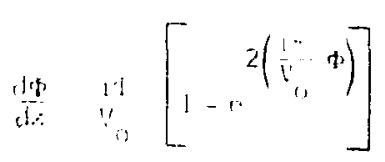

$$
\begin{aligned}
& 4 \\
& 14
\end{aligned}
$$

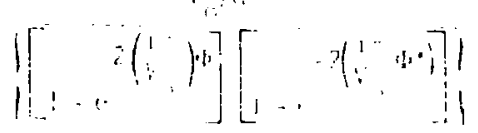

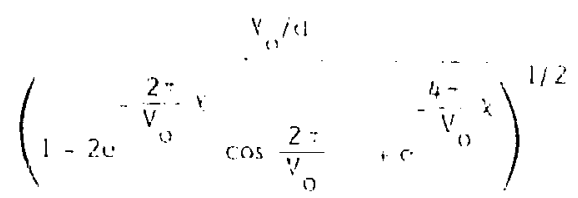

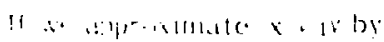

$$
\therefore \text { iy } \equiv i \frac{d}{v_{0}}+i \frac{d}{v_{0}} \cdot \frac{d}{v_{0}},
$$

$\therefore \cdots$

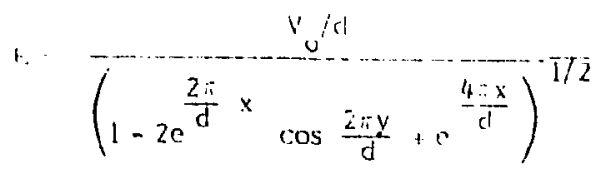

Whore the e.tge sf the plate is at $x=0$. This is the electrostatic field that thet cubroutine ELFD calculates as a function of $x$ and $y$.

The electrostatic fringe field along the midplane of the CENA system the it stuple form which can be easily derived from Eq. (18). In this case, $y=3$ an and (1) - form in the argument of the cosine term, so that 


$$
\begin{aligned}
& r=\frac{v_{0}^{1 d}}{\left[1-20^{\frac{2-}{6} \cdot x} \cos \left(\frac{2-3}{6}\right)+0^{\frac{4-}{4} \cdot x}\right]^{1 / 2}} \\
& v_{0} i^{d} \\
& {\left[1+2 e^{\frac{2-x}{d j}+x}+e^{d-x}\right]^{1 / 2}} \\
& \frac{V_{d}^{\prime} / 1}{1+e^{\frac{2 *}{d} \cdot x}}
\end{aligned}
$$

Equation (19) can be expressed in terms of a hyperbolit: tangent as follows:

$$
\begin{aligned}
& r=\frac{V_{0}}{d}\left[\frac{e^{-\frac{-}{2 d} \cdot x}}{e^{-\frac{i}{2 d} \cdot x}, e^{\frac{2 d}{2 d} \cdot x}}\right]
\end{aligned}
$$

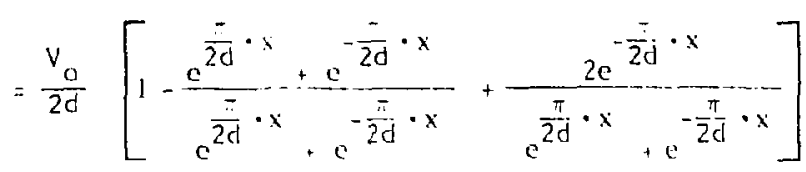

$$
\begin{aligned}
& \left.=\frac{V_{o}}{2 d}\left[1-\frac{\frac{\pi}{\partial d} \cdot x}{e^{-\frac{\pi}{2 d} \cdot x}}\right] e^{\frac{\pi}{2 d} \cdot x}+e^{-\frac{\pi}{2 d} \cdot x}\right] \\
& =\frac{v_{0}}{2 d}\left[1-\tanh \left(\frac{\pi}{2 d} \cdot x\right)\right] \text {. }
\end{aligned}
$$

We thus have a convenient analytic expression for modeling the behavior of the electrostatic field as a function of horizontal distance. This analytic form provides 


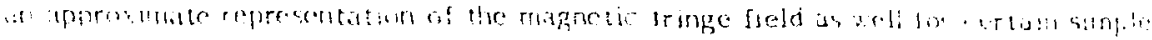

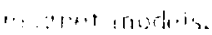

\section{V1. R:IS: ILTS}

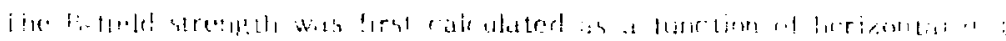

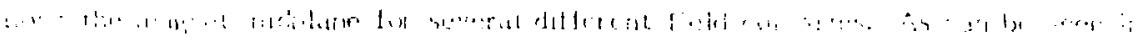

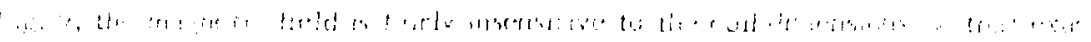

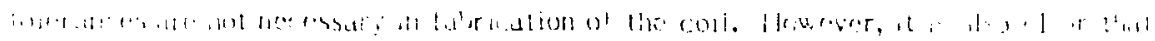

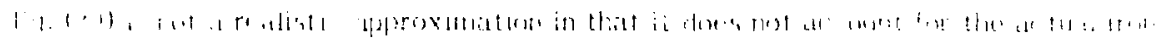

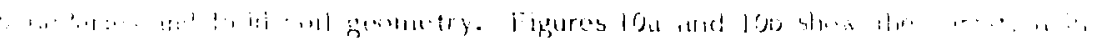

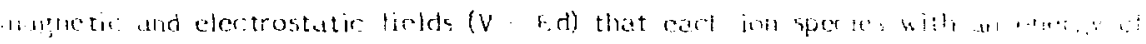

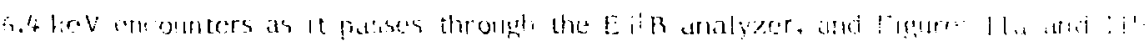

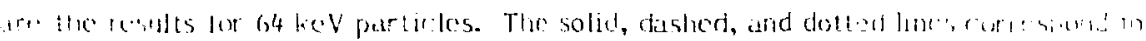

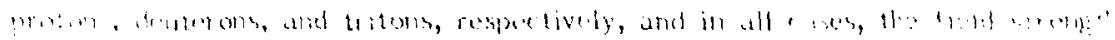

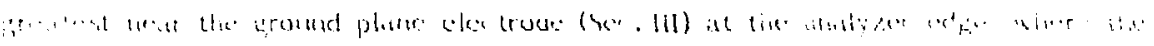

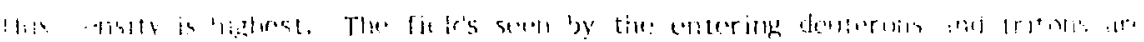

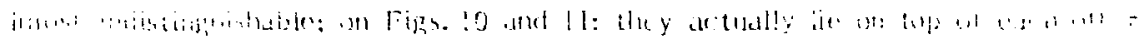

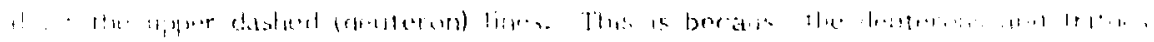

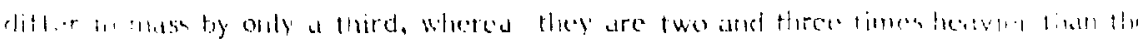

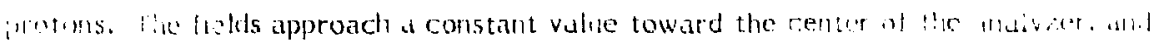

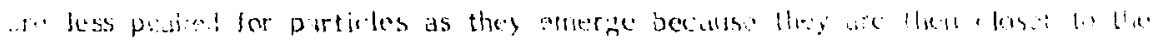
matem!ake or the magnet.

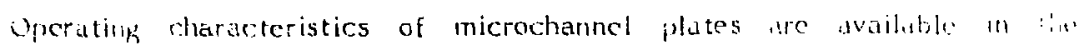

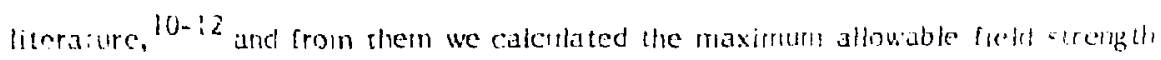
las the planted CENA geometry. This was found to be $\sim 50$ fs gatist, which is about :

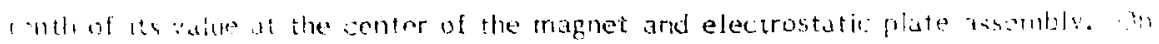

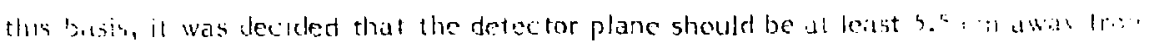
He poie and plate edge to satisfy this criterion (see Fig. 9). 
Maintaining the detectur plane parallel to, but displaced $5.5 \mathrm{~cm}$ beyond, the evit edge of the magnet is expected to distort the parallel, linear muss column geonctry which occurs for exuctly io $9^{\circ}$ de!lection in uniform fields is described in Ser. 11. From the equations of motion for an ion an a constant electric field, it is casy to show that beyond the mugnet exit, the vertical position $\hat{r}_{j}$ of speries (m/e), is friver by

$$
\hat{r}_{j}=r_{j} 1+\frac{45}{\pi z_{j k}}
$$

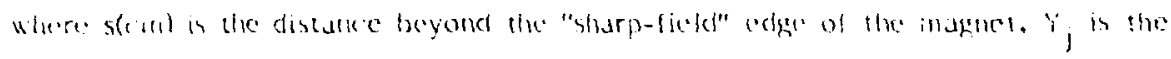
vertical position at the magnet eage given by Eq. (3), and $z_{j k}$ is the perpendicular vistance between the ingoing/outgoing ion trujectories Eq. (4). Thus [or $s>0$, the lower encrgy (smaller $Z_{j k}$ ) ions will exhibit a greater vertical displacement than those of higher energy. This behavior is evidenced in Fig. 12a, which show's the scatter of ions incident on the defector plane at $3-5.5 \mathrm{~cm}$ [or the "sharp-ficld" cuse, i.e., no mantetic or electric fringe ficits. Niso, it can be scen that the vertical width of the scater distribution for each in.s.s increases with increasing distance along the detecior plane. This occurs beraluse the detector plane provites in image through the stripping cell "pin-hole" of the source which has a distribution in space und angle of initial ion trajectories. The distance from the pin-hole trs the image plane, of course, increases with increasing distance along the detector planc.

The effect o: including the magnetic fringe field (no electric fringe ficld) is lllustrated in Fig. 12b. In seneral, the vertical deflection is reduced all alone curh mass column, the rediction being most pronounced at low energies. This occurs due to thr lact that no electric field exists in the portion of the particle tajectory through the magnetic fringe field. With derreasing energy, this portion incresses, thereby reducing the time the particle spends in the cicetric field and conscquently reducing the vertical deflection. 


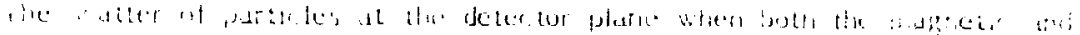

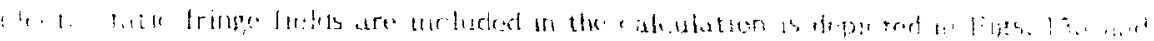

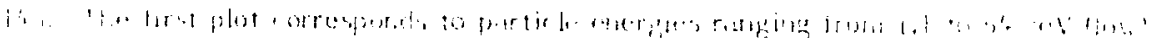

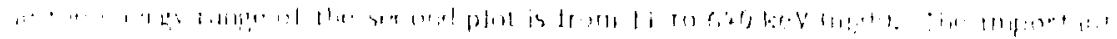

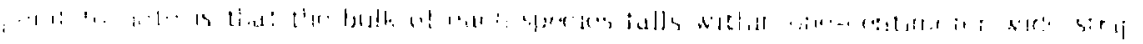

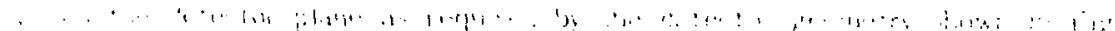

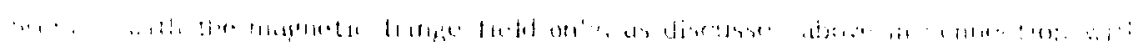
$\therefore$ !. .

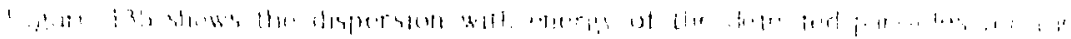

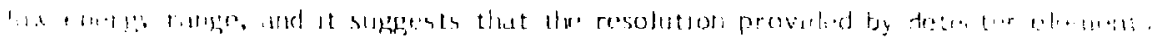

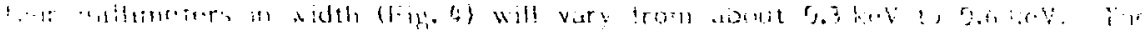

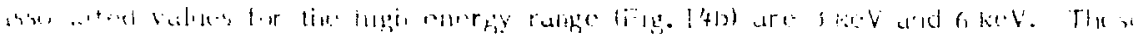

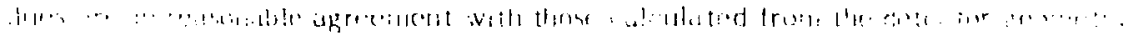
$(1,1014, \ldots: 1,1 .(3)$.

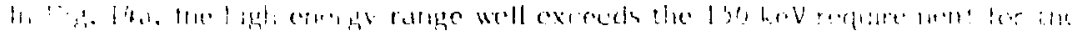

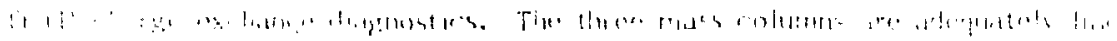

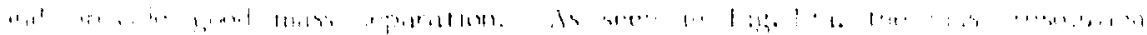

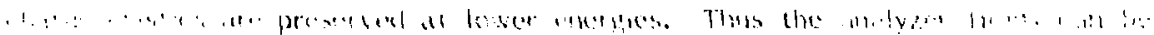

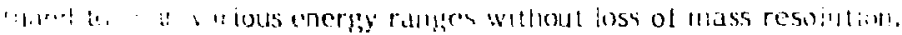

\section{CONELISIUNS}

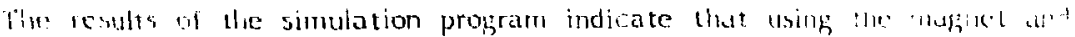

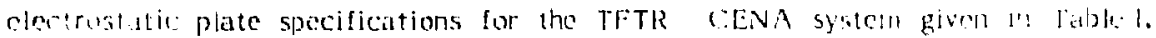
ipartirle; $\left(H^{\prime}, \mathrm{I}^{\prime}, \mathrm{T}^{+}\right)$over a broud energy range can be locused onto the detec tor

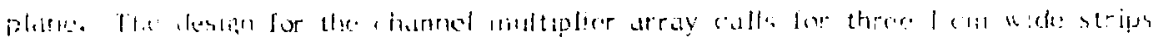

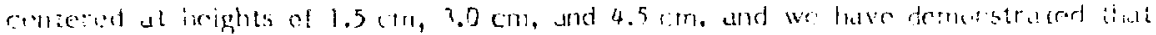


with reasonable plate potentids labout 0.6 kiluvnlts and 6 kilovolts for the low and high eneray ranges), the arrangement will enable the protons, deuterons, and tritous to be llass resolved over an energy range 11 excess of 0.5 to $150 \mathrm{keV}$.

\section{ACKNOWLEDGNENTS}

The authers would like to thaink U. Christensen and $s$. Drestin for developing the magnetic field code used in this work, and h. Whlfer for progrumbing assintunee. They are also gratelut to R. A. Sinlciston for hrinflll discussions. This ibort was sipported by the linited States hepariment of Energy Contruet No. EY-76-C.-02-3073. 


\section{REFERENCES}

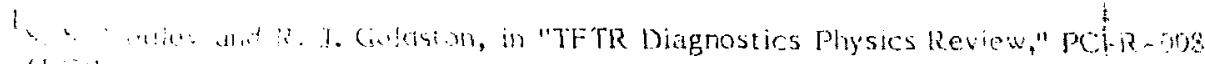
$11,1,1$.

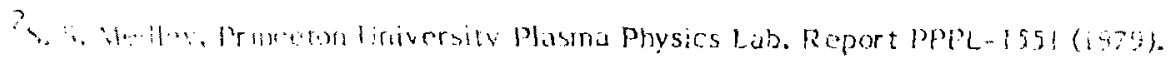

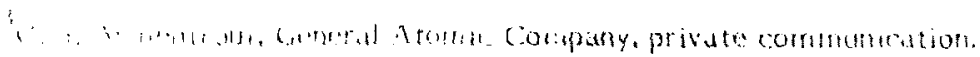

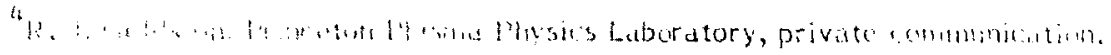

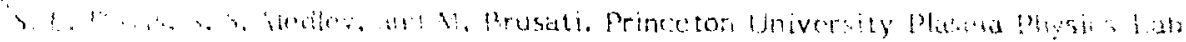

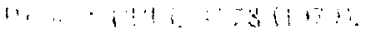

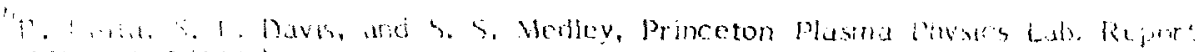

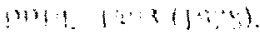

: . !

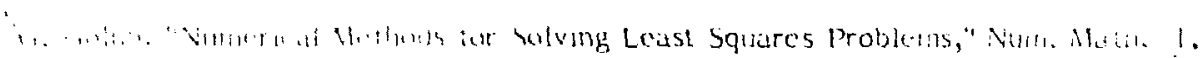

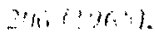

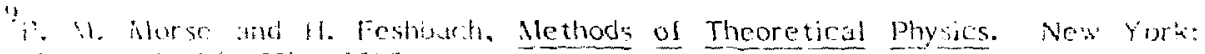

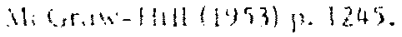

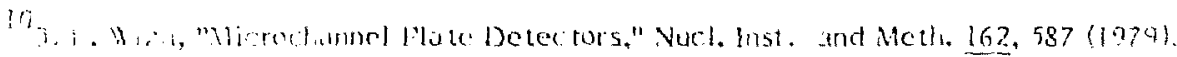

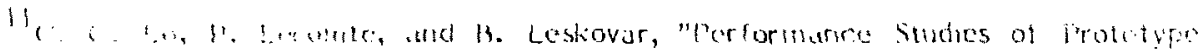

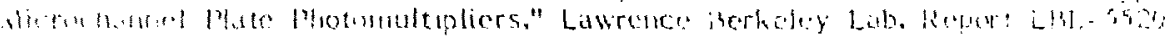

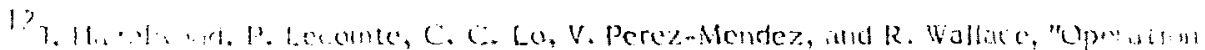

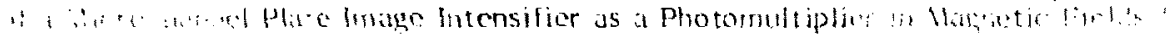

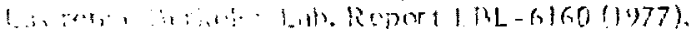


TABLE 1

\author{
WAGNET AND ELECTRIC FIELD SPECIFICATIONS \\ FUR THE TFTR CHARLE EXCHANGE NEUTRAL ANALYZER
}

1. Pole and Plate Dimensions

- 30 con dianeter semi-circle.

- $6 \mathrm{~cm}$ distance betweer pole faces.

- Approxirnately $5.5 \mathrm{~cm}$ distance between plate and ground plane (low'er magnet pole face).

2. rielı Coils

- Cross section of approximately $4 \mathrm{~cm} \times 6 \mathrm{~cm}$.

- Maximum of 14,400 ampere-turns (5.4 kilogauss field).

3. Voltage requirements

- DC voltage variable up to approximately 6 kilovorts. 


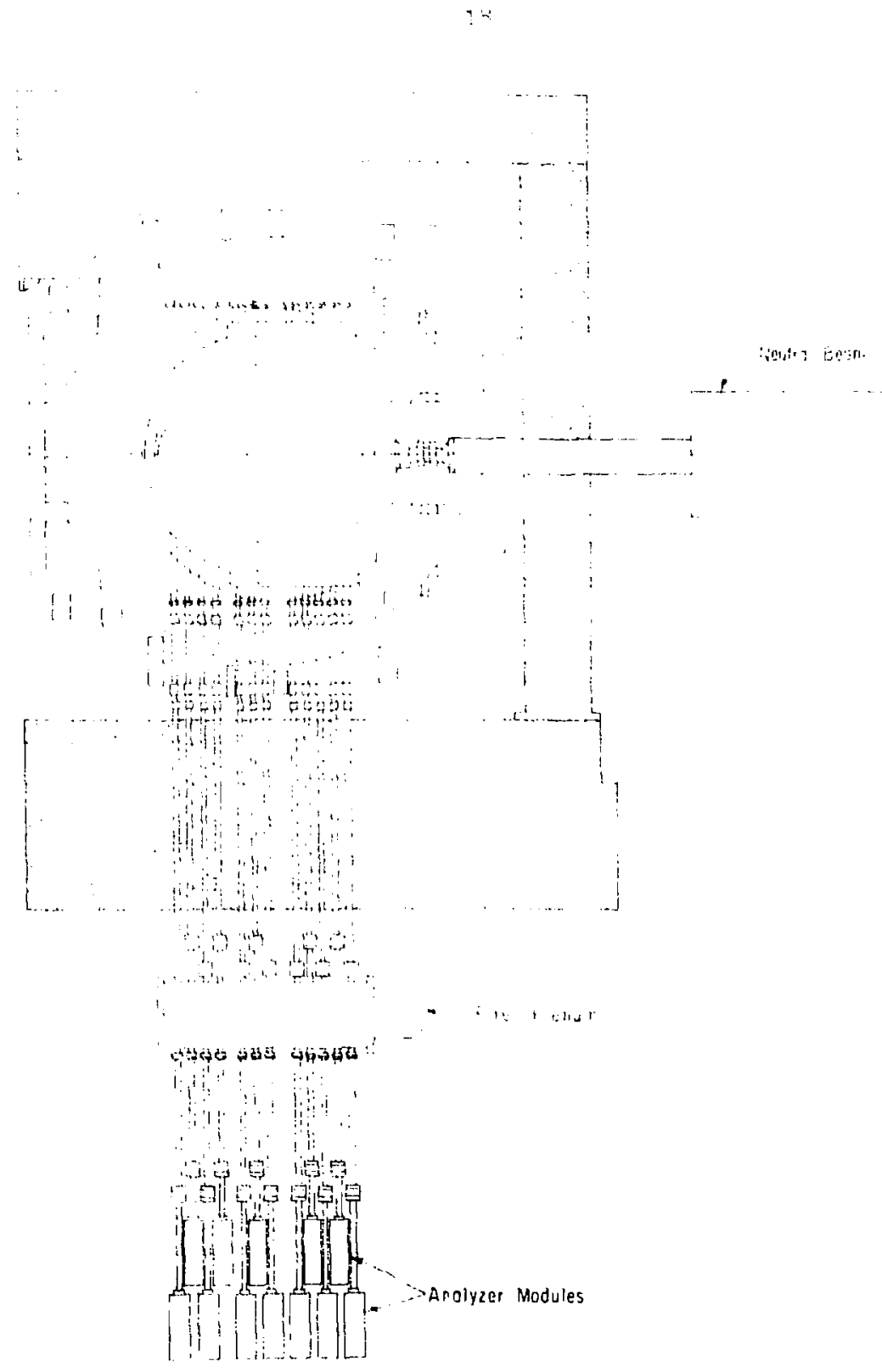

IPPL-793441

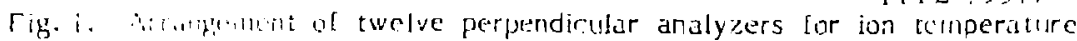
radial protilin measureaisints. 


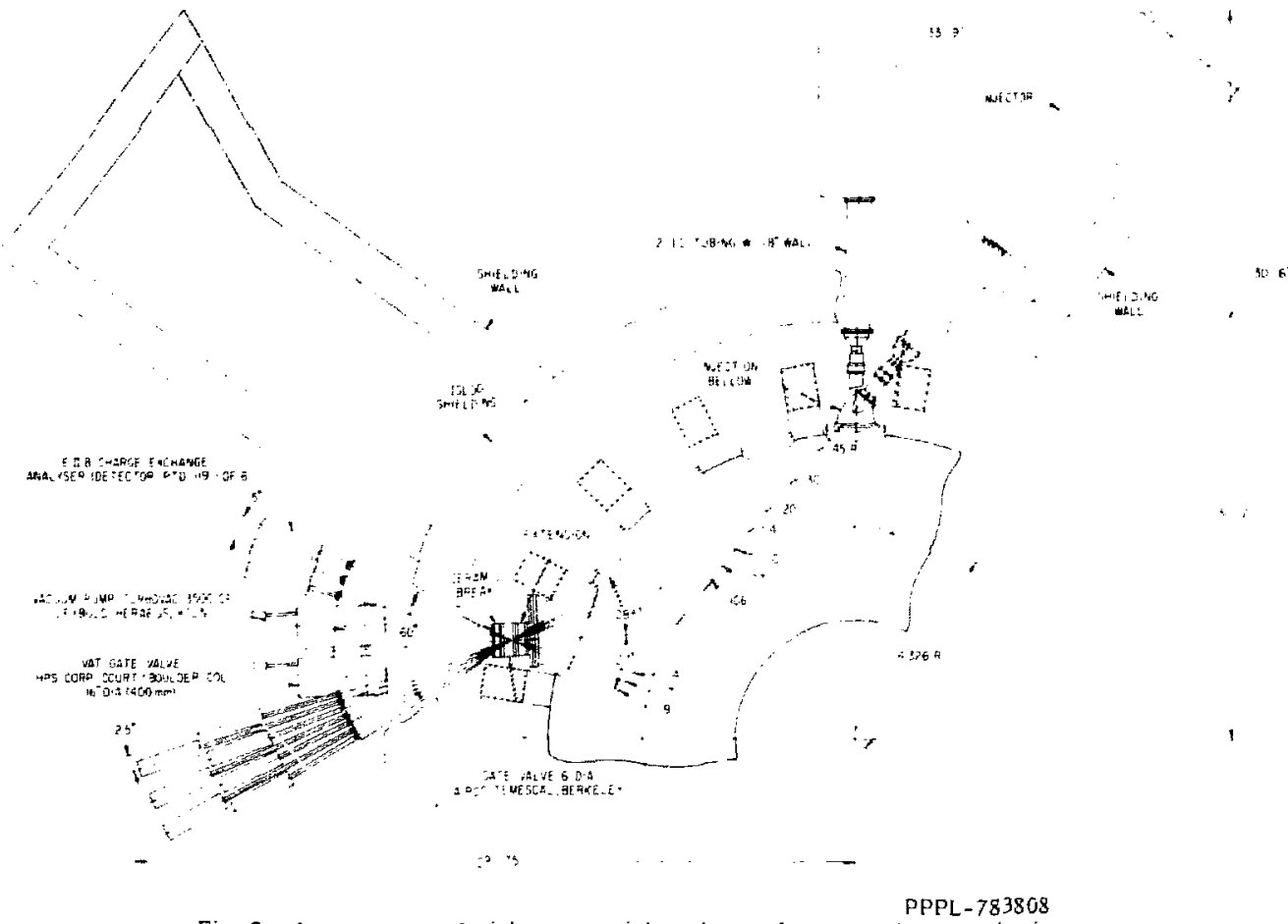

Fig. 2. Arrangerment of eight tangential analyzers for measuring the slowin down energy distribution of bearn-injected ions. 


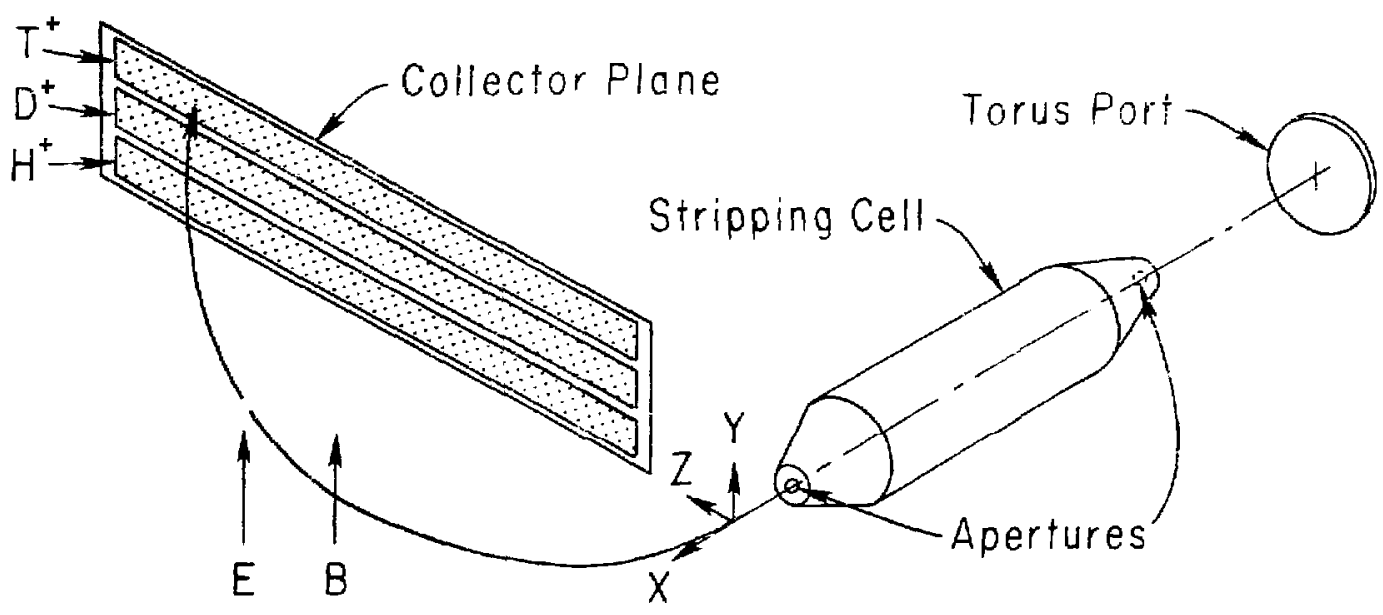

Fig. 3. Schematic of E:'3 andlyzer roncept.

PPPL-7:7825 


\section{LAYOUT OF THE CHANNEL MULTIPLIER ARRAY}

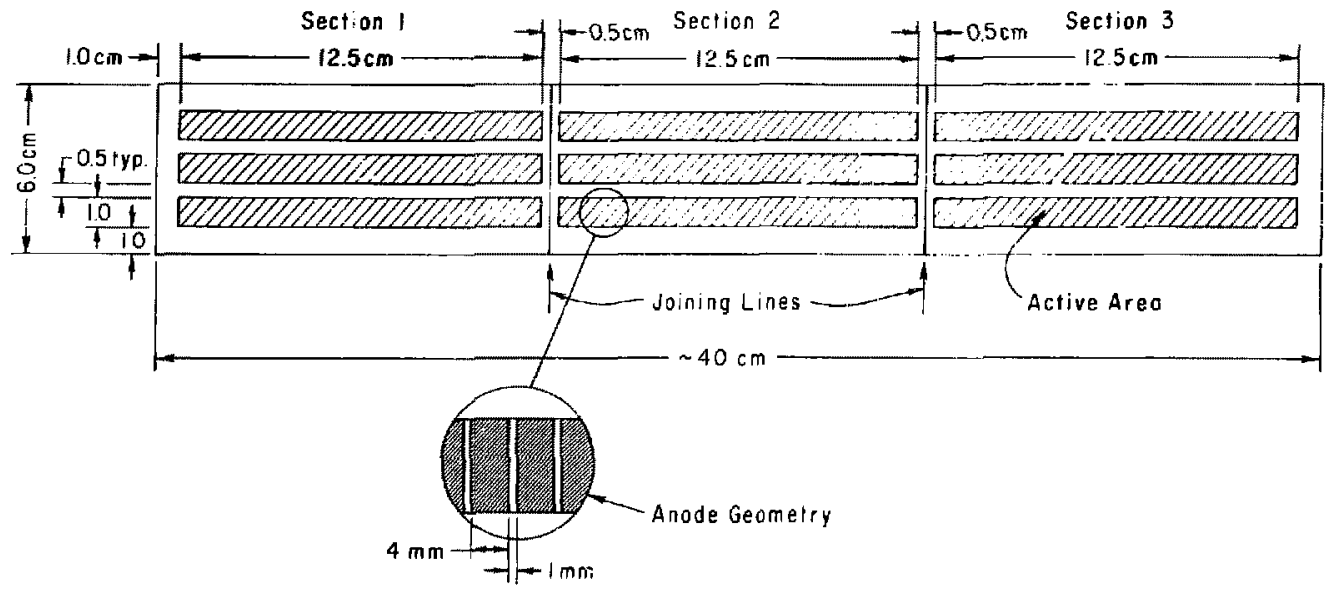

Fig. 4. Geometry of channel electron multiplier artay (C.E. A).

[PPPL - 78395] 


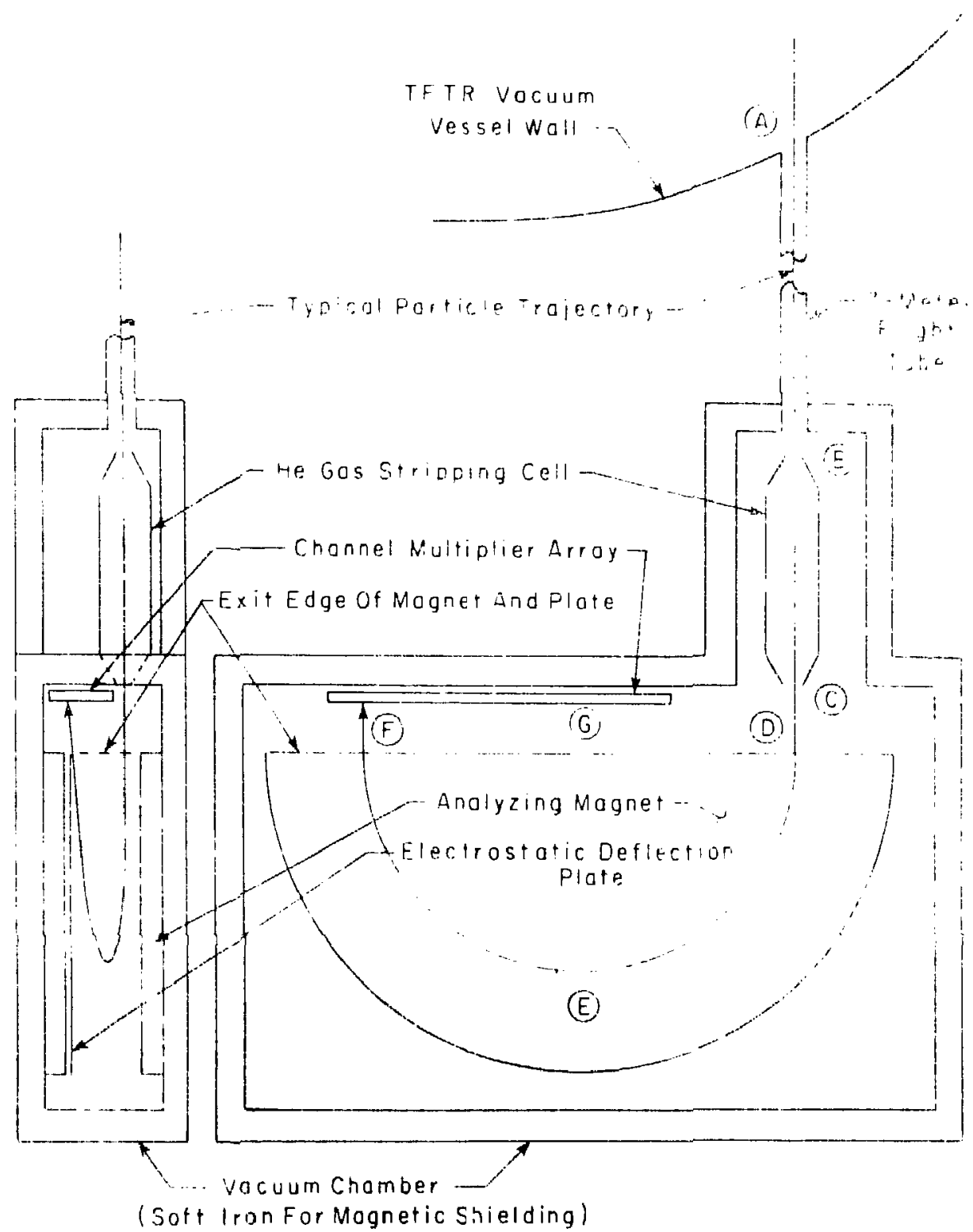

IPPL. 793889

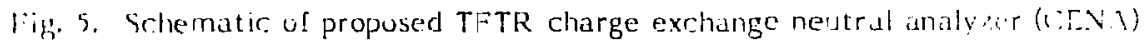
systerl. 


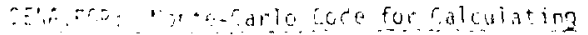

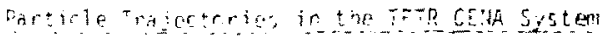

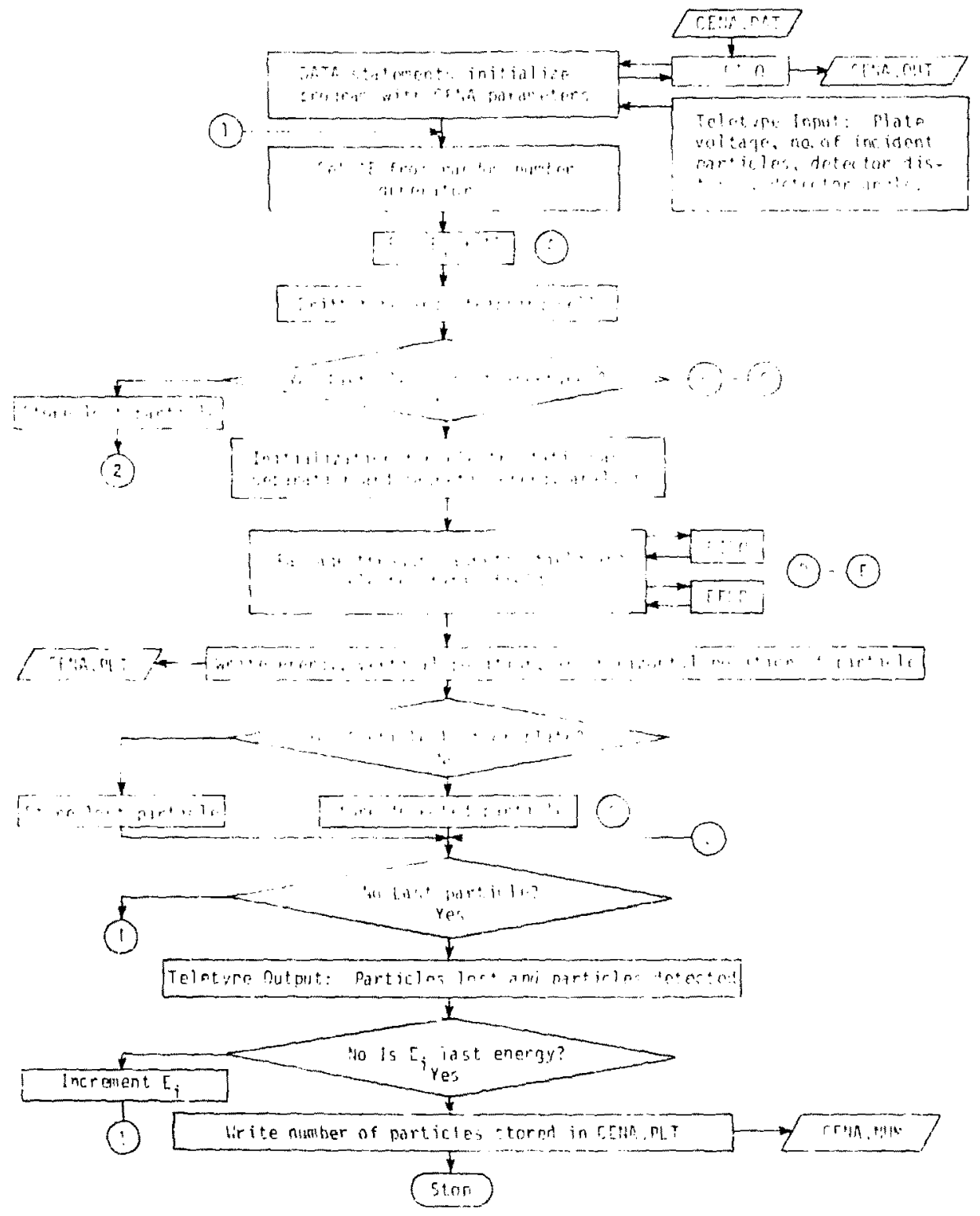

PPPL-793789

Fig. 6. Flowchart of Monte Carlo simulation prugram for calculating particle trajectories in the TFTR CENA system (CENA.FOR). 


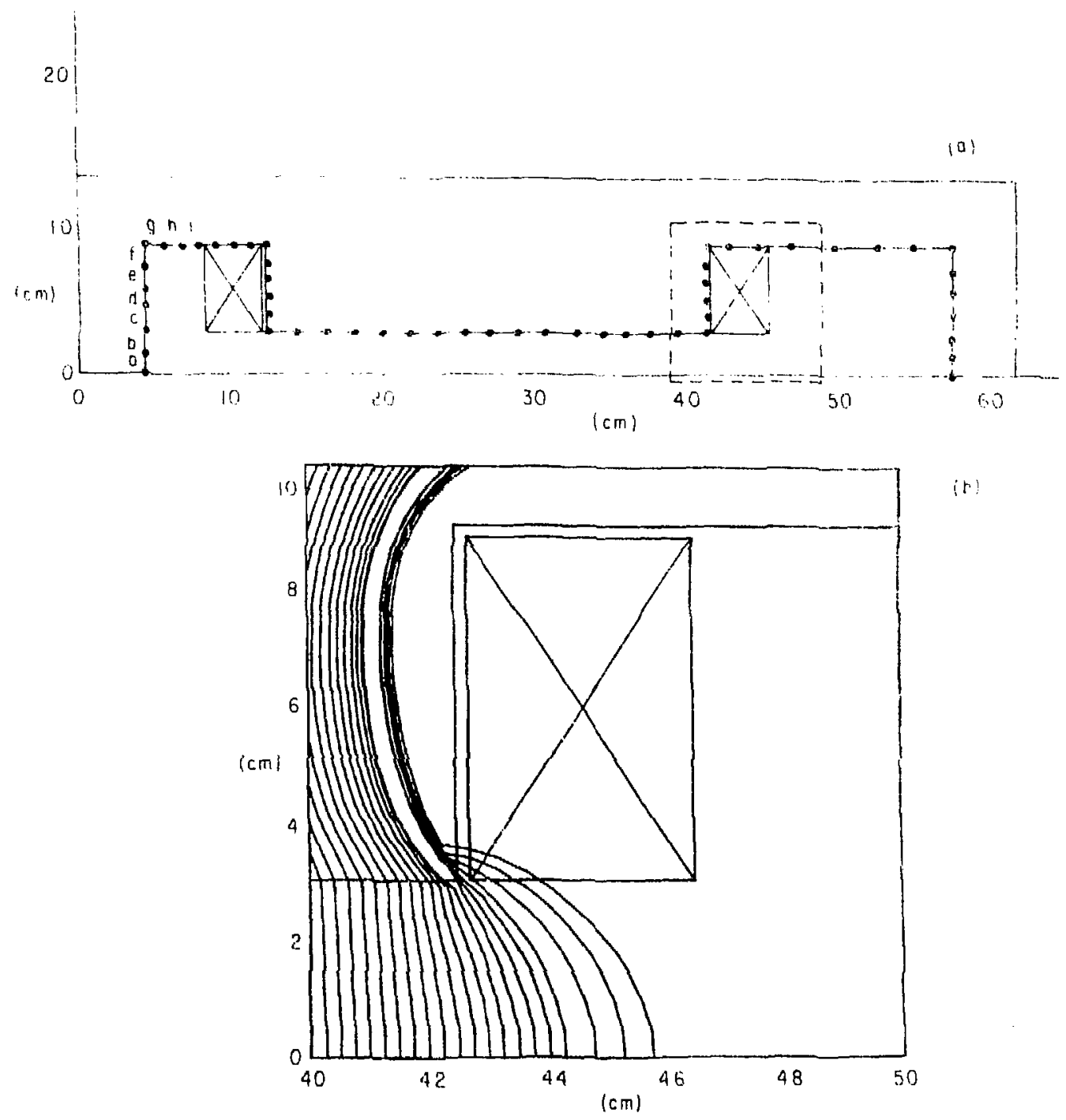

PPPL-793929

Fig. 7. Iron boundaries and field coil locations for B-field calculations usin. $F I B O(a)$ and enlargement of region around magnet field coil showing B-field lines (b). 

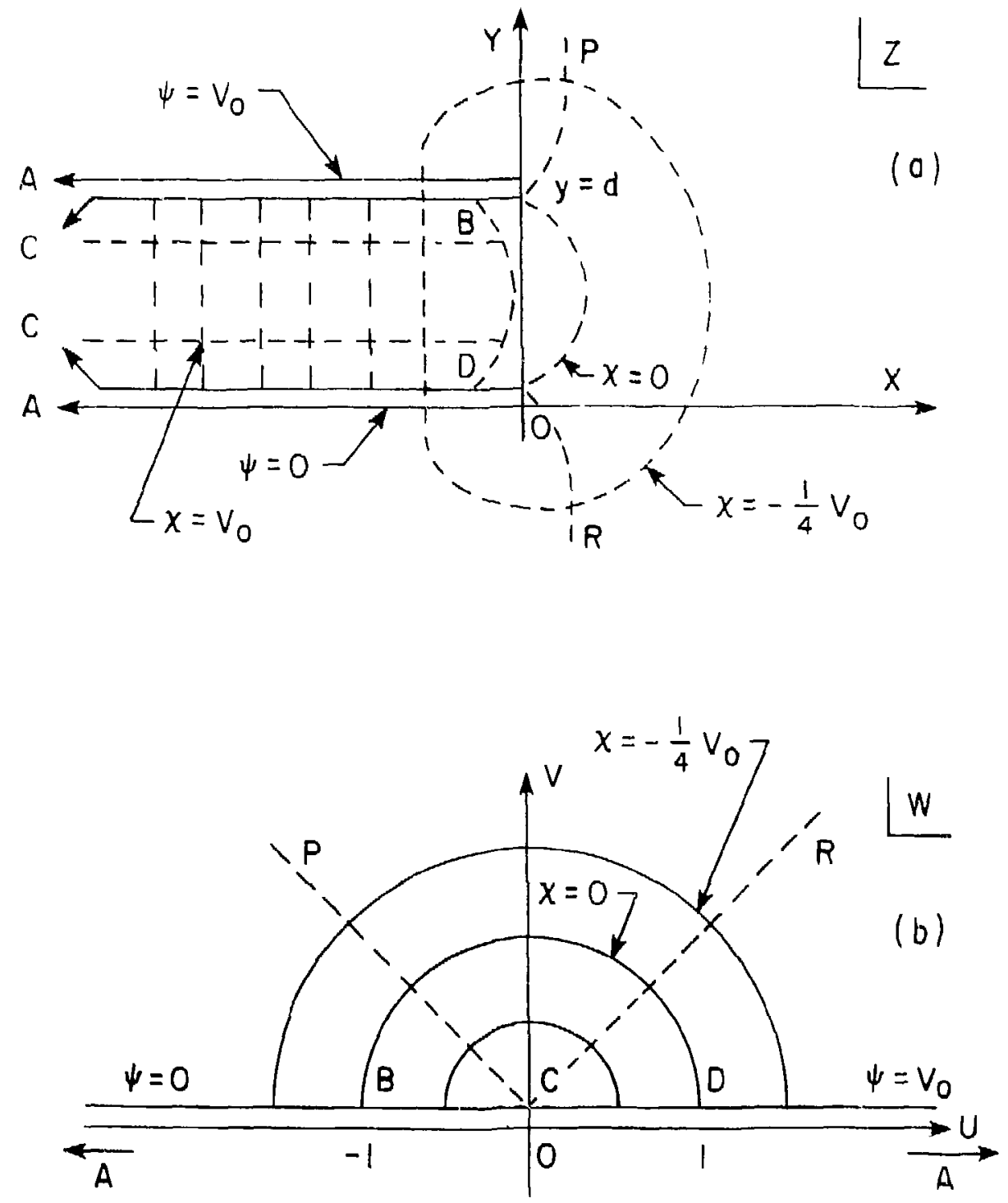

Fig. 8. Electrostatic Plate Configuration in the Z-Plane (a) and in the W-Plane (b). 


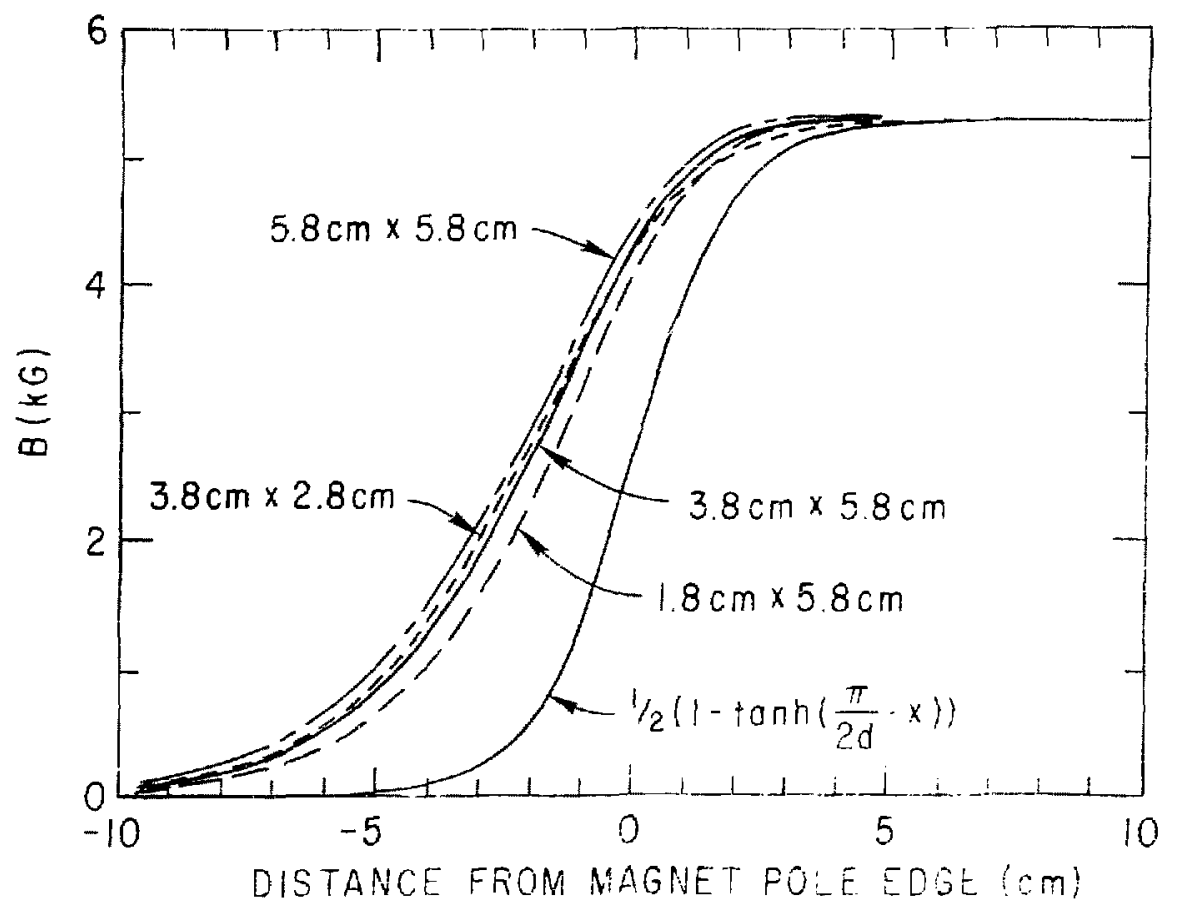



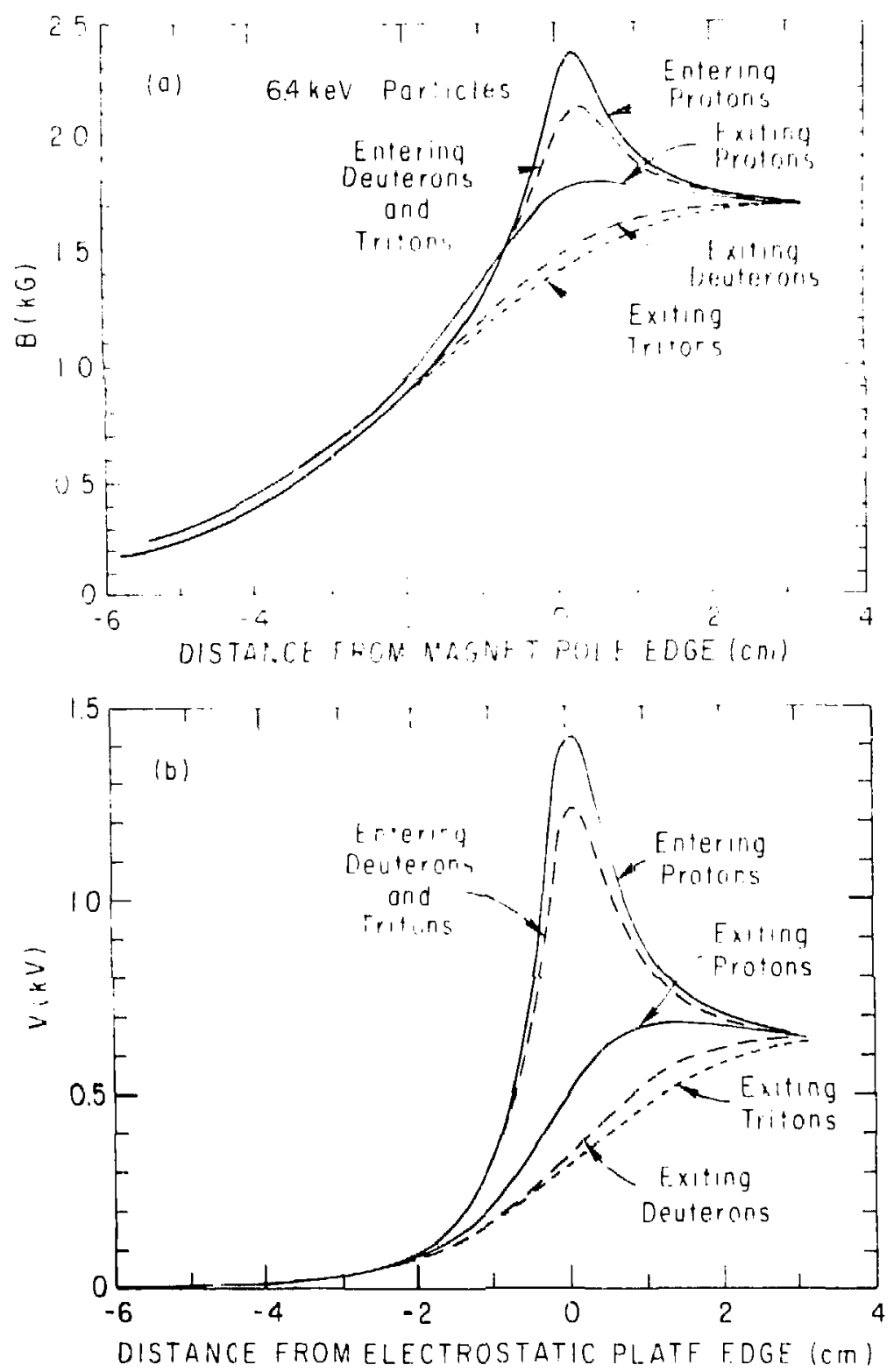

Fig. 10. B-fielo streng th (a) and $E$-field strength $(V=-d)(b)$ as a floction distance as seen by the three ion species (ion energy $=6.4 \mathrm{keV}$ ). 

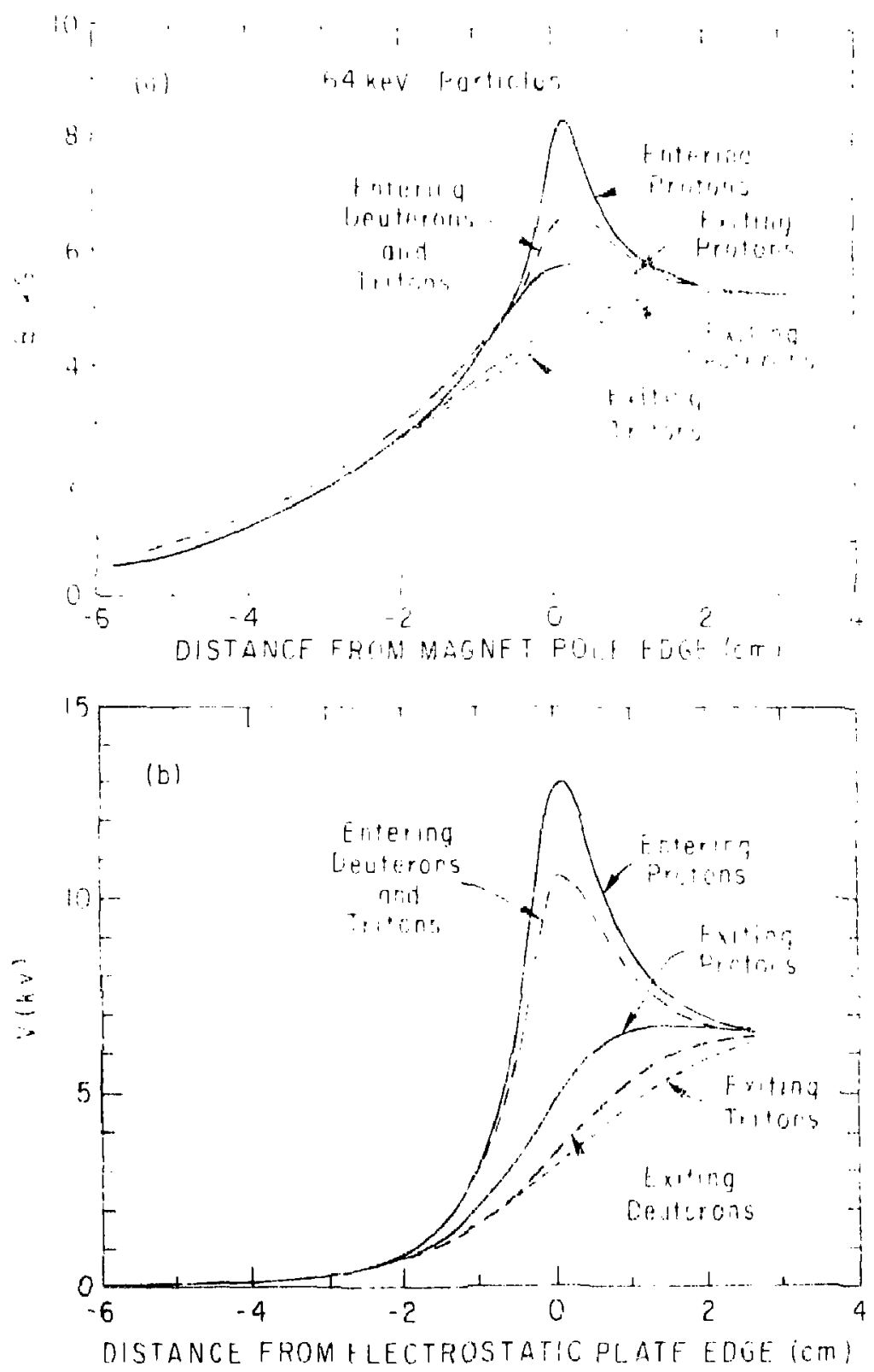

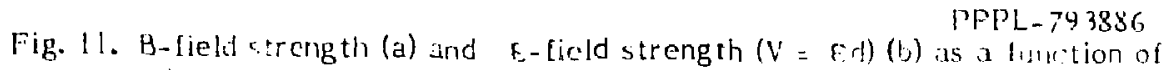
distance as seen by the three ion species (ion energy $=64 \mathrm{keV}$ ). 

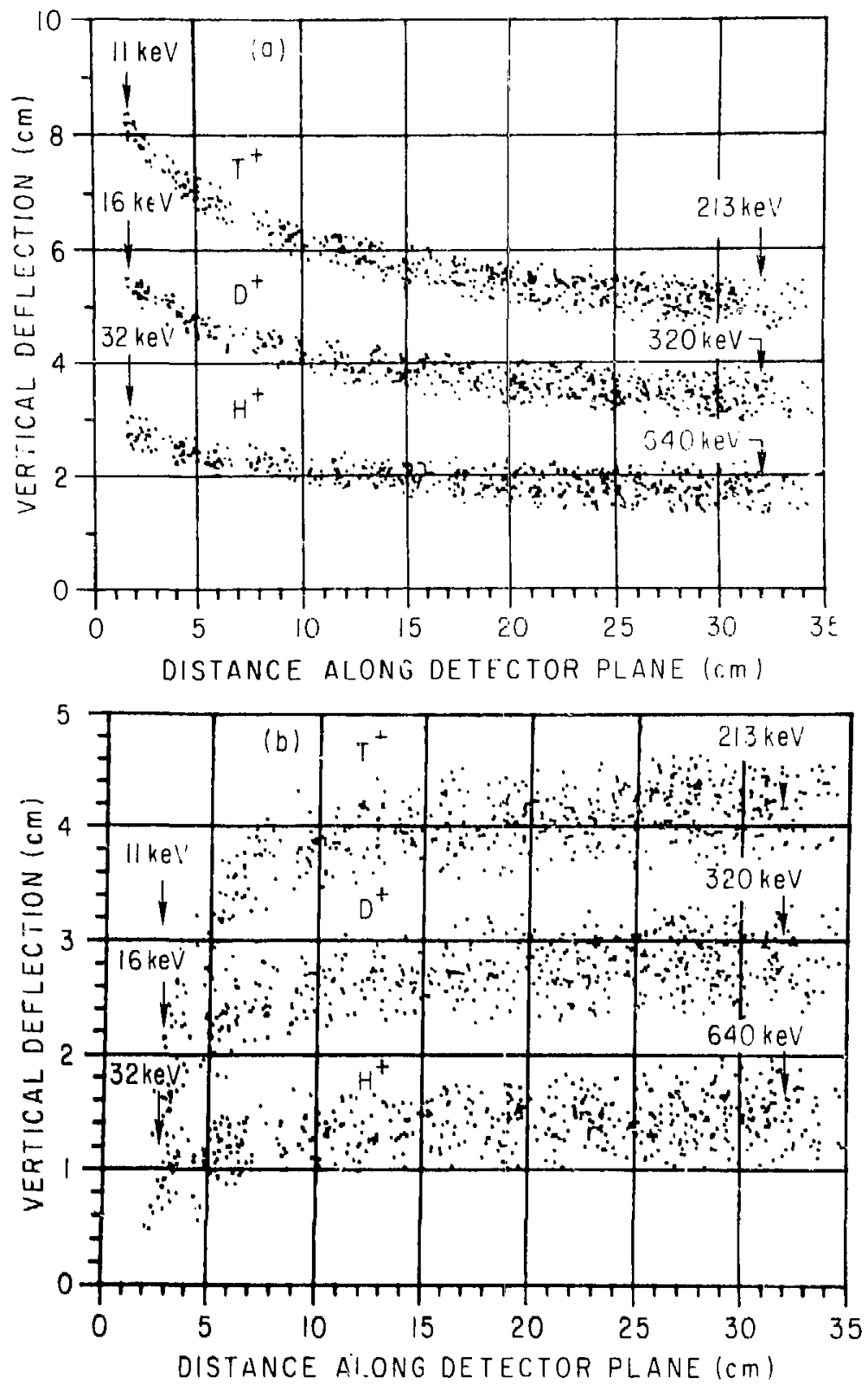

Fig. 12. Scatter plot of particles in the dotertor pline (a) without 793928 and (b) with inagnetic fringe tields only. 

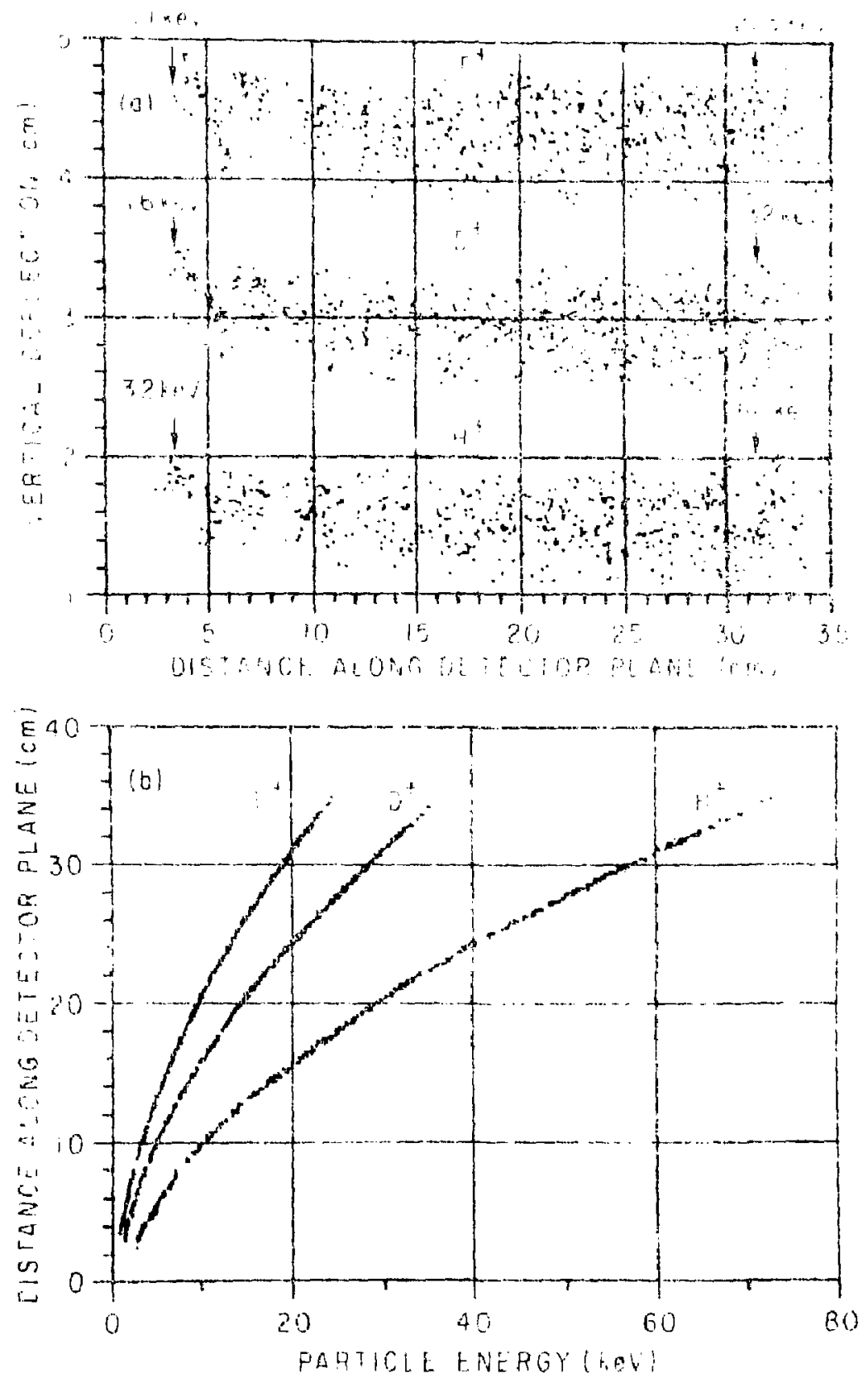

1919. - . 79384

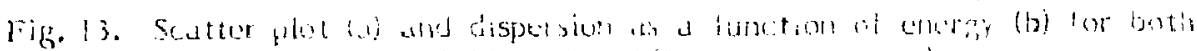

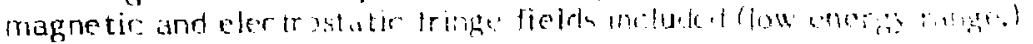



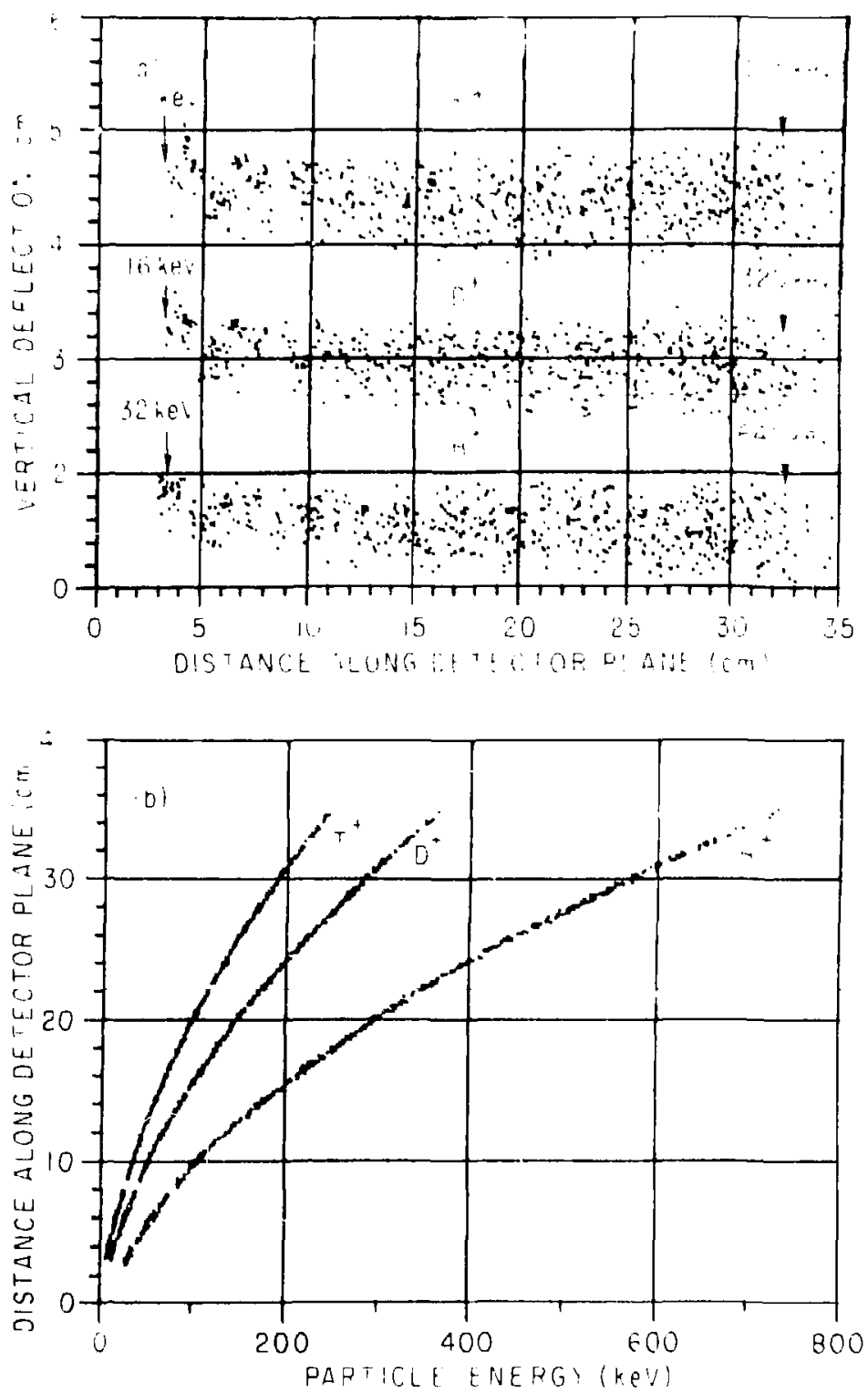

Fig. 14. Scatter plot (a) Pall'L-793890 inagnetic and electrustatic fringe fields included ('ygh ewerg) r.mgel. 